\title{
ANALISIS METODE PELAKSANAAN RETROFITTING PADA BANGUNAN SEDERHANA (STUDI KASUS : SD NEGERI 43 RAWANG TIMUR, PADANG)
}

\author{
Fauzan $^{1}$
}

\begin{abstract}
ABSTRAK
Indonesia merupakan negara kepulauan yang memiliki ancaman gempa bumi yang cukup tinggi. Indonesia terletak pada empat pertemuan lempeng tektonik utama yakni Eurasia, Indo-Australia, Pasifik, dan Filipina. Gempa bumi tidak dapat diprediksi namun usaha untuk meminimalisir kerusakan yang ditimbulkan dapat dilakukan pada bangunan. Salah satunya dengan melakukan tindakan retrofit pada bangunan sederhana (non-engineered) yang mengalami kerusakan akibat bencana gempa. Penelitian ini bertujuan untuk mengetahui metoda pelaksanaan yang tepat dan efisien dalam melakukan perbaikan, restorasi, dan perkuatan bangunan sederhana. Dengan menggunakan prinsip teknik yang benar, detail konstruksi yang baik dan praktis maka kerugian harta benda dan jiwa menusia yang diakibatkan gempa bumi dapat dikurangi untuk masa yang akan datang. Penelitian ini juga bertujuan untuk mengetahui besarnya efisiensi dari segi biaya dan waktu dalam pekerjaan retrofit yang dilakukan pada bangunan.
\end{abstract}

Kata Kunci :retrofit, perbaikan, restorasi, perkuatan, efisiensi.

\section{PENDAHULUAN}

Gempa bumi berkekuatan besar kembali mengguncangwilayah tanah air tepatnya di bagian barat Provinsi Sumatera Barat. Berdasarkan informasi dariBadan Meteorologi Klimatologi dan Geofisika (BMKG, 2009) kekuatan gempa diperkirakan berkisar7,6 SR dengan pusat gempa berada pada koordinat 0.84 LS - 99.65 BT pada kedalaman $71 \mathrm{~km}$ didasar laut dan berjarak $57 \mathrm{~km}$ arah barat daya Pariaman, Sumatera Barat.

Gempa tektonik yang terjadi pada tanggal 30 September 2009 lalu telah mengakibatkan berbagai kerusakan baik sarana maupun prasarana fisik serta korban jiwa pada berbagai daerah di Provinsi Sumatera Barat. Berdasarkan data yang diterbitkan Satkorlak PB Provinsi Sumatera Barat dan BNPB diketahui sektor infrastruktur mengalami kerusakan dan kerugian mencapai Rp.963 miliar. Sektor pendidikan juga mengalami kerusakan akibat gempa.Sebanyak 1.384 bangunan sekolah rusak berat, 1.018 rusak sedang, dan 744 rusak ringan dengan nilai kerusakan sebesar Rp.588,7 miliar.

Khusus kota Padang, pasca gempa 30 September 2009 yang lalu, banyak bangunan sekolah yang mengalami kerusakan. Bangunan-bangunan ini termasuk bangunan sederhana (non-engineered buildings). Bangunan non-engineered merupakanbangunan rumah tinggal dan bangunan komersial sampai dua lantai yang dibangun oleh pemilik dengan menggunakan tukang setempat, menggunakan bahan bangunan yang didapat di daerah setempat, tanpa bantuan arsitek maupun ahli struktur.Agar proses belajar mengajar dapat dijalankan secepatnya, diperlukan tindakan rehabilitasi pada bangunan yang disebut dengan retrofitting.Retrofit terdiri dari tindakan perbaikan, restorasi, dan perkuatan.Salah satu bangunan sekolah yang mengalami kerusakan dan dilakukan tindakan

${ }^{1}$ Dosen Jurusan Teknik Sipil Fakultas Teknik Universitas Andalas, e-mail: fauzan@ft.unand.ac.id 
retrofit di kota Padang ini adalah SD Negeri 43 Rawang Timur, yang terletak pada Kecamatan Padang Selatan (Gambar 1.).

Penelitian ini bertujuan untuk mengetahui metode retrofit yang diterapkan pada perbaikan dan perkuatan komponen struktur dan non-struktur bangunan serta mengetahui besarnya efisiensi pekerjaan retrofit pada bangunan SD ini dari segi biaya dan waktu.

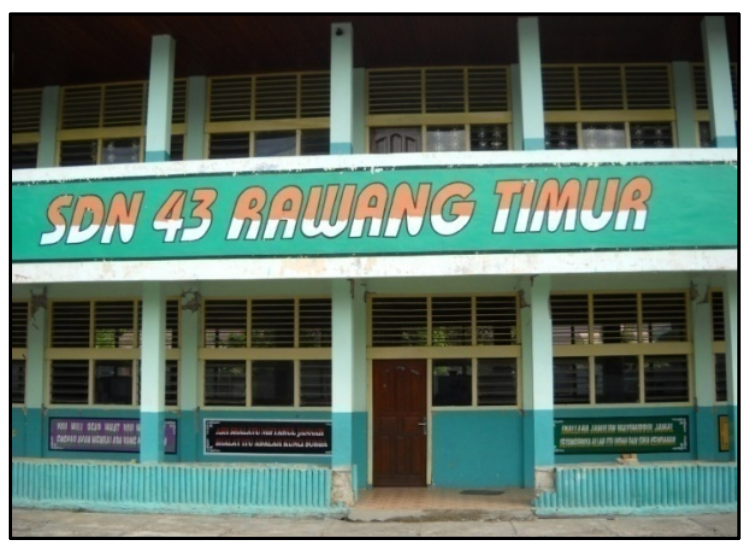

Gambar 1. SD Negeri 43 Rawang Timur

\section{HASIL EVALUASI VISUAL KERUSAKAN DAN PELAKSANAAN}

SD Negeri 43 ini terletak di daerah Rawang Timur, Kecamatan Padang Selatan, Kota Padang. Bangunan utama sekolahnya terdiri dari 2 lantai. Pada masing-masing lantai terdapat 3 ruangan kelas dan sebuah ruangan yang berfungsi sebagai kantor. Luas total bangunannya $408 \mathrm{~m}^{2}$.

\subsection{Data-Data Kerusakan}

\section{a. Kerusakan Pada Kolom}

Bangunan SD Negeri 43 ini terdiri dari 2 lantai dengan jumlah kolom 39 buah berukuran 20x20 $\mathrm{cm}$. Pada umumnya kerusakan kolom yang terjadi pada bangunan sekolah ini terjadi pada bagian atas dan bawah yaitu mulai dari kerusakan kecil seperti lepasnya plesteran pada kolom, hancurnya sebagian selimut beton hingga selimut beton yang rusak sampai terlihat tulangan yang ada pada kolom(Gambar 2.). Kolom juga mengalami retak pada bagian joint antara kolom dan balok.

Ketika kolom dibobok terlihat pada sambungan kolom dan balok tidak adanya tulangan penyaluran sepanjang 40D. Hal ini membuat bangunan tidak menjadi sebuah kesatuan yang utuh dalam menahan beban. Selain itu, jarak tulangan geser lebih besar dari $15 \mathrm{~cm}$ dan banyak tulangan geser ini yang lepas dari tulangan utamanya.

\section{b. Kerusakan Pada Balok}

Kerusakan yang banyak terjadi pada balok gedung SD Negeri 43 ini adalah retak pada bagian sambungan antara kolom dan balok. Ini menunjukkan adanya sesuatu yang salah pada sambungan tulangan antara kolom dan balok tersebut sehingga terjadi pergeseran dan bangunan tidak bergetar sebagai suatu kesatuan yang utuh, padahal konsep bangunan aman gempa adalah setiap elemen struktur bekerja sebagai suatu kesatuan yang utuh dalam menahan beban. Pada balok melintang di bangunan gedung sekolah ini adanya perubahan dimensi. Dimensi balok yang berada di dalam

\section{2 | JURNAL REKAYASA SIPIL}


kelas lebih besar dari balok yang di luar kelas. Pada bagian ini juga terlihat adanya tulangan penyaluran yang tidak sesuai (Gambar 3.).

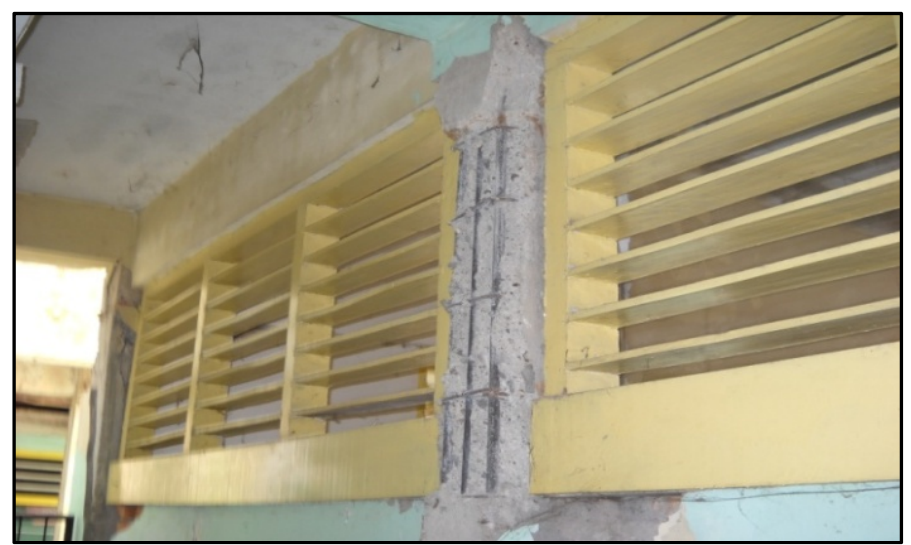

a.

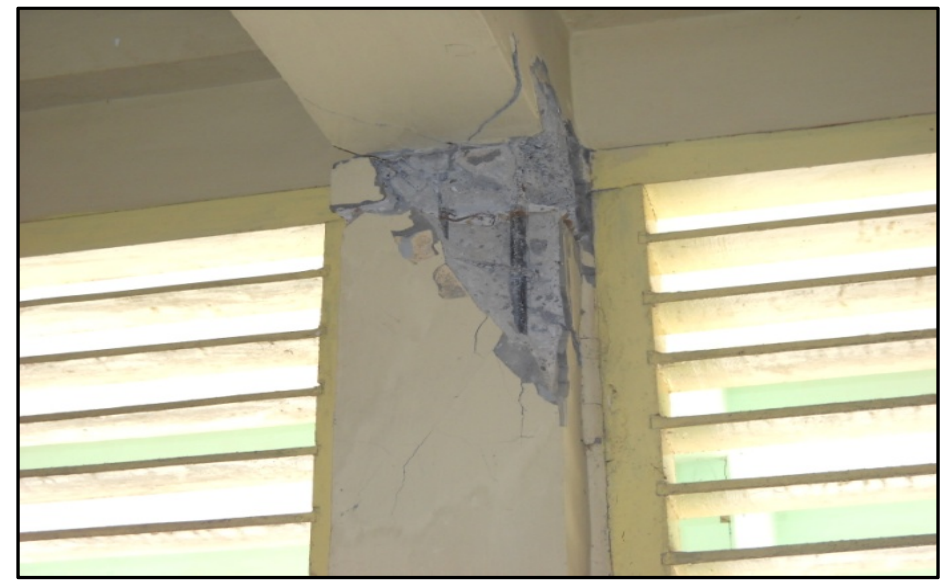

b.

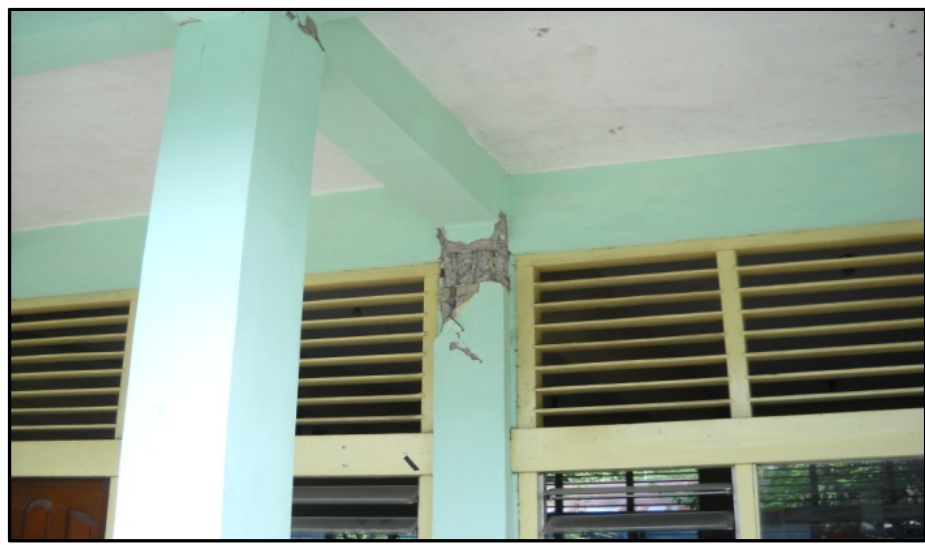

c.

Gambar 2. Kerusakan Pada Kolom (a, b, c) 


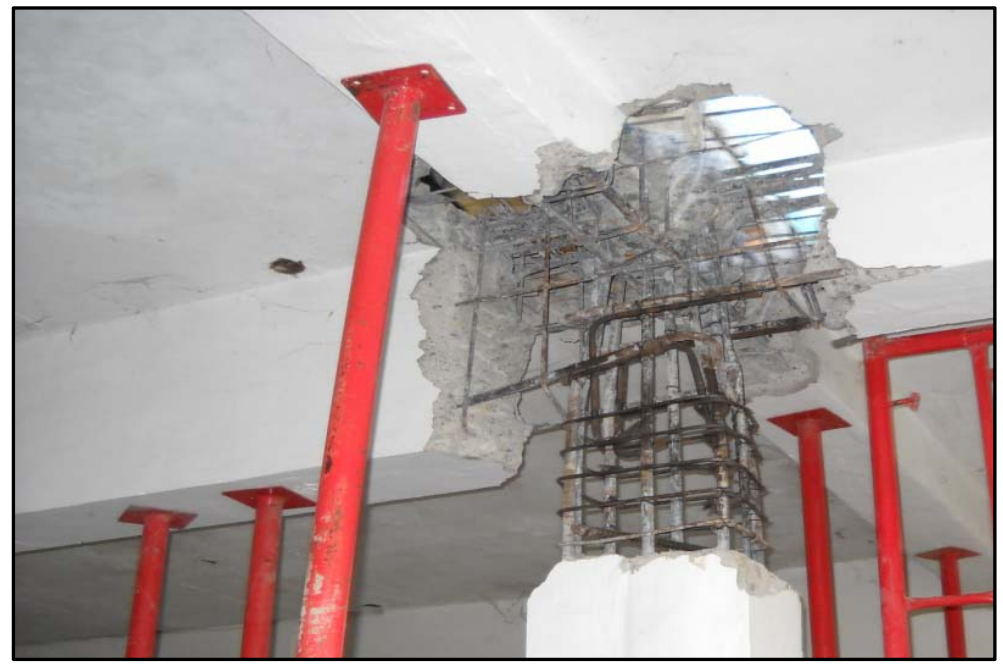

Gambar 3. Kerusakan Pada Balok

c. Kerusakan Pada Dinding

Pada bangunan SD Negeri 43 ini kerusakan pada dinding yang terlihat hanya berupa retak-retak kecil. Pada sebagian pertemuan sudut-sudut dinding dengan kolom juga terlihat adanya kerusakan pada dinding berupa retak serta lepasnya plesteran dari dinding. Pada bagian tengah dinding kebanyakan hanya berupa retak-retak halus saja (Gambar 4.).

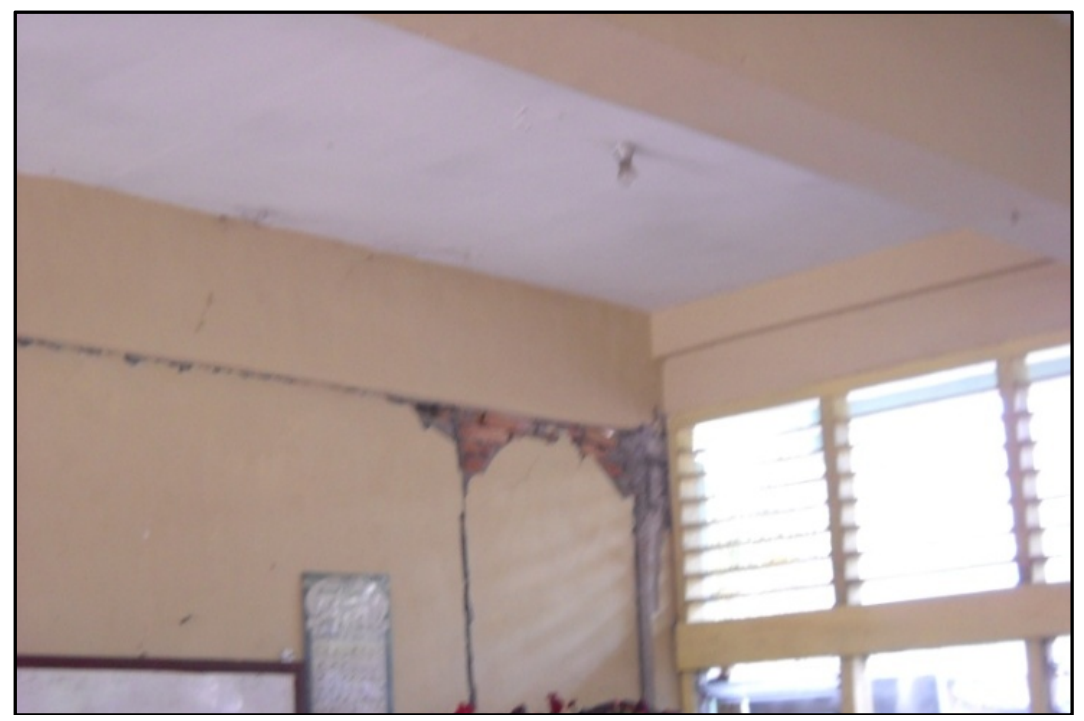

Gambar 4. Kerusakan Pada Dinding

\subsection{Metede Perbaikan, Restorasi, dan Perkuatan}

Kerusakan yang terjadi pada bangunan sekolah SD Negeri 43 ini terletak pada bagian struktur dan arsitekturnya. Kerusakan pada bagian struktur antara lain pada sambungan kolom dan balok dan dari segi arsitekturnya kerusakan pada bagian dinding. Adapun penentuan metode dan material

\section{J URNAL REKAYASA SIPIL}


perbaikan umumnya tergantung pada jenis kerusakan yang ada, disamping besar dan luasnya kerusakan yang terjadi, lingkungan dimana struktur berada, peralatan yang tersedia, kemampuan tenaga pelaksana serta batasan-batasan dari pemilik seperti keterbatasan ruang kerja, kemudahan pelaksanaan, waktu pelaksanaan dan biaya perbaikan.

\subsubsection{Metode Perbaikan Kolom dan Balok}

Beberapa metode perbaikan kolom yang dapat digunakan adalah:

a. Menambah jumlah tulangan dan melakukan penjangkaran sambungan kolom-balok serta merapatkan jarak sengkang kolom. Pada metode ini bagian kolom atau balok yang mengalami kerusakan dibobok. Kemudian dilakukan penjangkaran sambungan kolombalok, sepanjang 40D. Sengkang kolom dan balok juga dirapatkan. Metode ini mudah untuk dilakukan dan tidak membutuhkan pekerja yang banyak dan juga peralatan yang sederhana.

b. Menambah jumlah tulangan dan sengkang di luar kolom / balok beton, kemudian ditutup kembali dengan coran beton/jacketing (Gambar 5). Dengan penambahan dimensi kolom akan menambah kapasitas dukung kolom. Dalam penelitian Kawashima et.al (1997), metode jacketing dapat meningkatkan kapasitas aksial kolom metode jacketing ini banyak digunakan apalagi telah dikembangkan dengan bahan material komposit seperti FRP (Fiber Reinforced Polymer), GFRP (Glass Fiber Reinforced Polymer), dan CFRP (Carbon Fiber Reinforced Polyimer.).

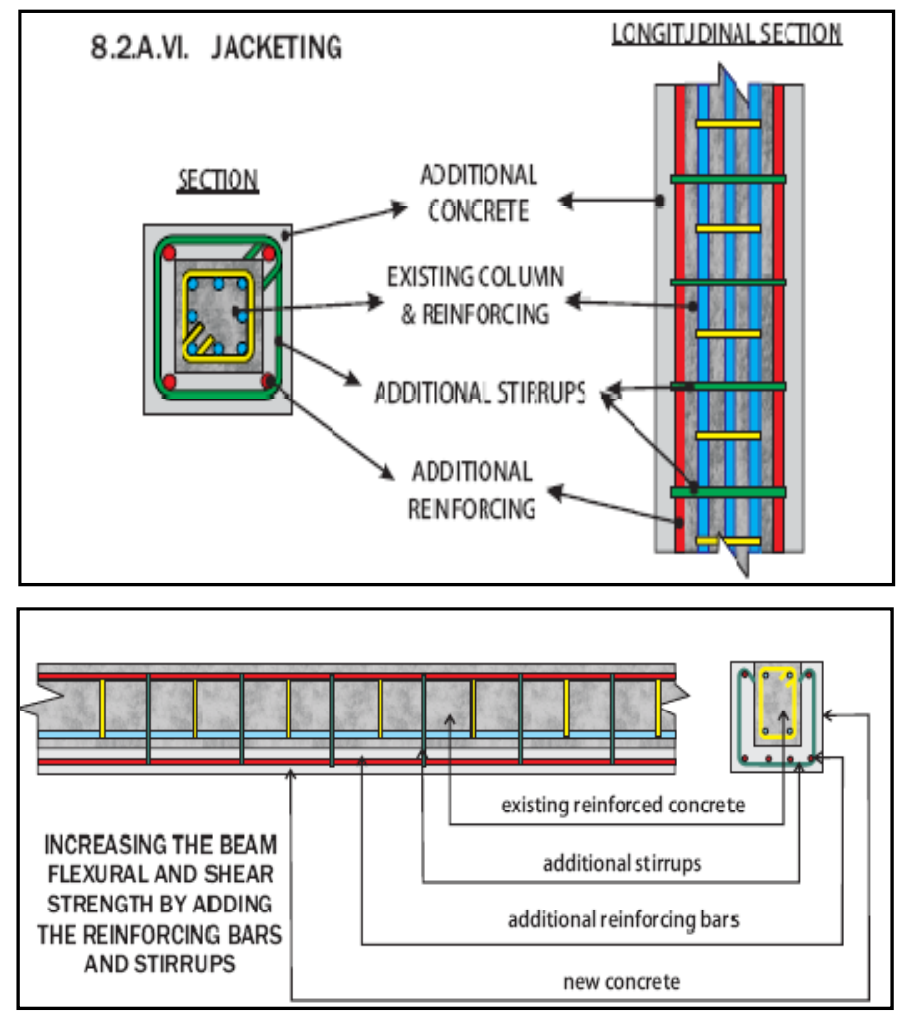

Gambar 5. Jacketting Pada Kolom dan Balok (Boen, 2009) 


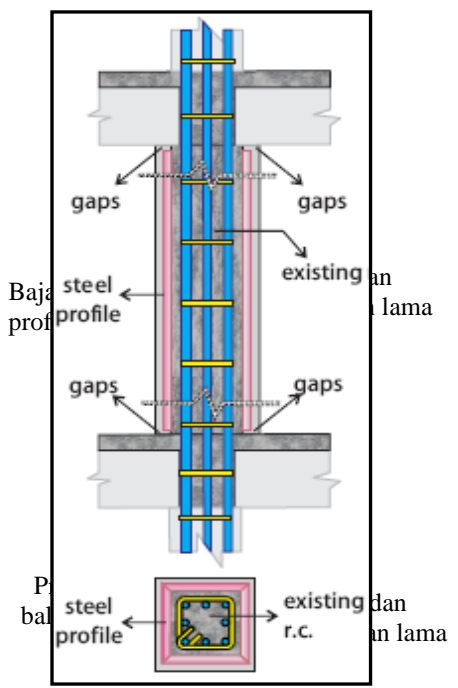

Gambar 6. Penambahan Profil Baja Pada Kolom(Boen, 2009)

c. Menyelubungi kolom beton dengan profil baja persegi dan kemudian grouting celah-celah antara beton dan baja (Gambar 6). Metode ini membutuhkan waktu dan pekerja yang intensif, selain itu akan menimbulkan beban mati tambahan pada struktur, dan juga perlekatan (bonding) antara beton baru dengan beton lama bisa saja kurang sempurna karena kesalahan pada saat pemasangannya.

\subsubsection{Metode Perbaikan Dinding}

Beberapa metode perbaikan dinding rusak yang dapat digunakan adalah:

a. Merubuhkan sebagian / seluruh permukaan dinding. Dinding yang mengalami kerusakan cukup besar dapat dirubuhkan lalu dibangun kembali dinding baru.

b. Menggunakan metode injeksi. Retak pada dinding yang mengalami kerusakan dilakukan tindakan injeksi campuran pasta semen dengan expanding agent lalu dilakukan pelapisan pada permukaan dinding dengan bahan polymer mortar. Metode injeksi ini dapat dilakukan secara manual atau menggunakan mesin bertekanan, tergantung pada besar dan dalamnya keretakan.

c. Menggunakan kawat anyam. Kawat anyam digunakan untuk memperbaiki dinding dengan keretakan $>5 \mathrm{~mm}$. Kawat anyam dipasang pada kedua sisi dinding dengan cara mengikatnya satu sama lain. Untuk dinding retak $<5 \mathrm{~mm}$, cukup dengan mengisi retak dengan air semen kemudian diplester kembali.

\subsection{Pelaksanaan Retrofitting SD Negeri 43 Rawang Timur}

Dari hasil evaluasi kerusakan SD Negeri 43 Rawang Timur metode yang efektif digunakan adalah dengan metode penjangkaran kolom-balok serta merapatkan jarak sengkang. Ini dikarenakan kerusakan terjadi pada jointbalok. Penggunaan metode ini cukup efisien karena tidak membutuhkan banyak pekerja serta penggunaan alatnya pun sederhana.

Pelaksanaan perkuatan kolom tersebut dilakukan secara bersamaan dengan langkah-langkah sebagai berikut (Gambar 7):

a. Bagian bawah dari balok yang berada di sekeliling kolom yang akan diperkuat atau ditopang dengan menggunakan support baja. Setelah itu bagian pelat lantai ditopang dengan scafolding, dengan tujuan agar beban-beban yang berasal dari lantai atasnya dapat

\section{6 | JURNAL REKAYASA SIPIL}


ditopang. Pada proyek bangunan ini bagian kolom dan pelat lantai pada bagian selasar yang akan di-retrofit terlebih dahulu maka bagian tersebut harus ditopang terlebih dahulu.

b. Setelah balok ditopang, selanjutnya seluruh selimut beton pada bagian tersebut dibobok dengan panjang bobokan $\pm 60 \mathrm{~cm}$ dari tepi kolom. Selimut beton kolom juga dibuka pada bagian atas serta bawahnya sekitar $\pm 60 \mathrm{~cm}$ dengan menggunakan alat demolition hammer. Sehingga kondisi tulangan akan terlihat.

c. Setelah selimut beton kolom dan balok selesai dibobok, lalu tulangan geser pada bagian kolom yang dibuka akan ditambah untuk merapatkan tulangan geser yang ada, karena jarak tulangan geser yang ada terlalu jauh. Jarak minimum yang diperlukan adalah $8 \mathrm{~cm}$. Diameter tulangan yang digunakan adalah Ø $8 \mathrm{~mm}$.

d. Buat sambungan kolom-balok dengan mengikuti kaedah bangunan aman gempa yaitu pembengkokan tulangan sepanjang $40 \mathrm{D}$. Tulangan yang dilebihkan yaitu tulangaan utama balok dan kolom. Hal ini dimaksudkan agar bangunan menjadi kaku, sehingga ketika digoyang gempa, bangunan menjadi kaku, dan mengalami goncangan sebagai satu kesatuan.

e. Sebelum melakukan pengecoran, terlebih dahulu pada bagian pelat lantai 2 dibuat lubang di sekeliling kolom yang gunanya mempermudah pengecoran bagian atas kolom dan juga sambungan balok dan kolom. Ukuran lubang bukaan sekitar $60 \mathrm{~cm}$. Lubang dibuat dengan menggunakan demolition hammer.

f. Bekisting kemudian dipasangkan pada bagian atas dan bawah kolom. Bekisting pada bagian bawah kolom dibuat berbentuk corong pada ujungnya guna memudahkan adukan beton masuk pada saat pengecoran. Bekisting dibuat dari bahan triplek dan kayu 5/7.

g. Selanjutnya adukan beton dipersiapkan, dengan campuran 1 semen : 2 pasir : 3 split. Adukan beton dibuat dengan menggunakan molen. Pada saat pengadukan, ditambahkan sikka, yaitu sejenis zat aditif yang berfungsi untuk mempercepat pengerasan beton. Komposisi campurannya adalah $200 \mathrm{ml}$ sikka untuk 1 zak semen.

h. Selanjutnya pengecoran dilakukan pada bagian atas dan bawah kolom. Pada saat pengecoran adukan beton yang masuk ke bekisting harus ditusuk-tusuk dengan menggunakan sebilah besi serta bekisting dipukul untuk membuat adukan beton tidak bertumpuk pada satu bagian, sehingga agregatnya merata dan tidak terjadi pemisahan agregat.

i. Pembukaan bekisting dapat dilakukan 2 hari setelah dilakukan pengecoran.

j. Setelah bekisting dibuka, lalu kolom tersebut disiram dengan air setiap hari selama satu minggu. Penyiraman dilakukan untuk menjaga kelembaban kolom agar kolom tidak rusak/retak.

k. Setelah bekisting dibuka, bagian beton pada bawah kolom yang berlebih dapat dibongkar.

l. Setelah coran beton pada bagian atas kolom mengering, pelat lantai dapat ditutup kembali dengan keramik.

Adapun metode yang dipergunakan untuk perbaikan pada kerusakan dinding adalah dengan menginjeksikan air semen pada retak-retak dinding. Hal ini dilakukan karena jenis kerusakan pada dinding bangunan SD ini ternasuk jenis retak kecil/halus. Langkah-langkah metoda pelaksanaan yang dilakukan untuk perbaikan retak pada sudut dinding yaitu :

a. Pelaksanaan perbaikan dinding yang mengalami kerusakan pada bagian ujung-ujungnya dilakukan bersamaan pada saat pengecoran kolom. Luas dinding yang rusak ini tak lebih dari $1 \mathrm{~m}^{2}$.

b. Bagian dinding yang rusak dibongkar dengan menggunakan pahat sebesar luas kerusakan yang ada.

c. Selanjutnya kolom yang berada pada pertemuan dengan dinding diperbaiki seperti cara memperbaiki kolom yang dijelaskan sebelumnya.

d. Dinding yang rusak ditambah dengan bata baru, lalu bekisting dibuat sekaligus untuk bekisting dinding. 
e. Pengecoran dinding dilakukan bersamaan dengan pengecoran kolom.

Langkah-langkah metoda pelaksanaan yang dilakukan untuk perbaikan retak pada sudut dinding yaitu :

a. Kerusakan pada dinding hanya berupa rusak halus, dengan demikian tidak perlu memakai kawat anyam.

b. Plesteran lama di sekitar retak dikupas $+50 \mathrm{~cm}$ lalu diisi dengan air semen.

c Setelah celah rapat, dinding diplester kembali dengan campuran spesi 1 semen : 3 pasir
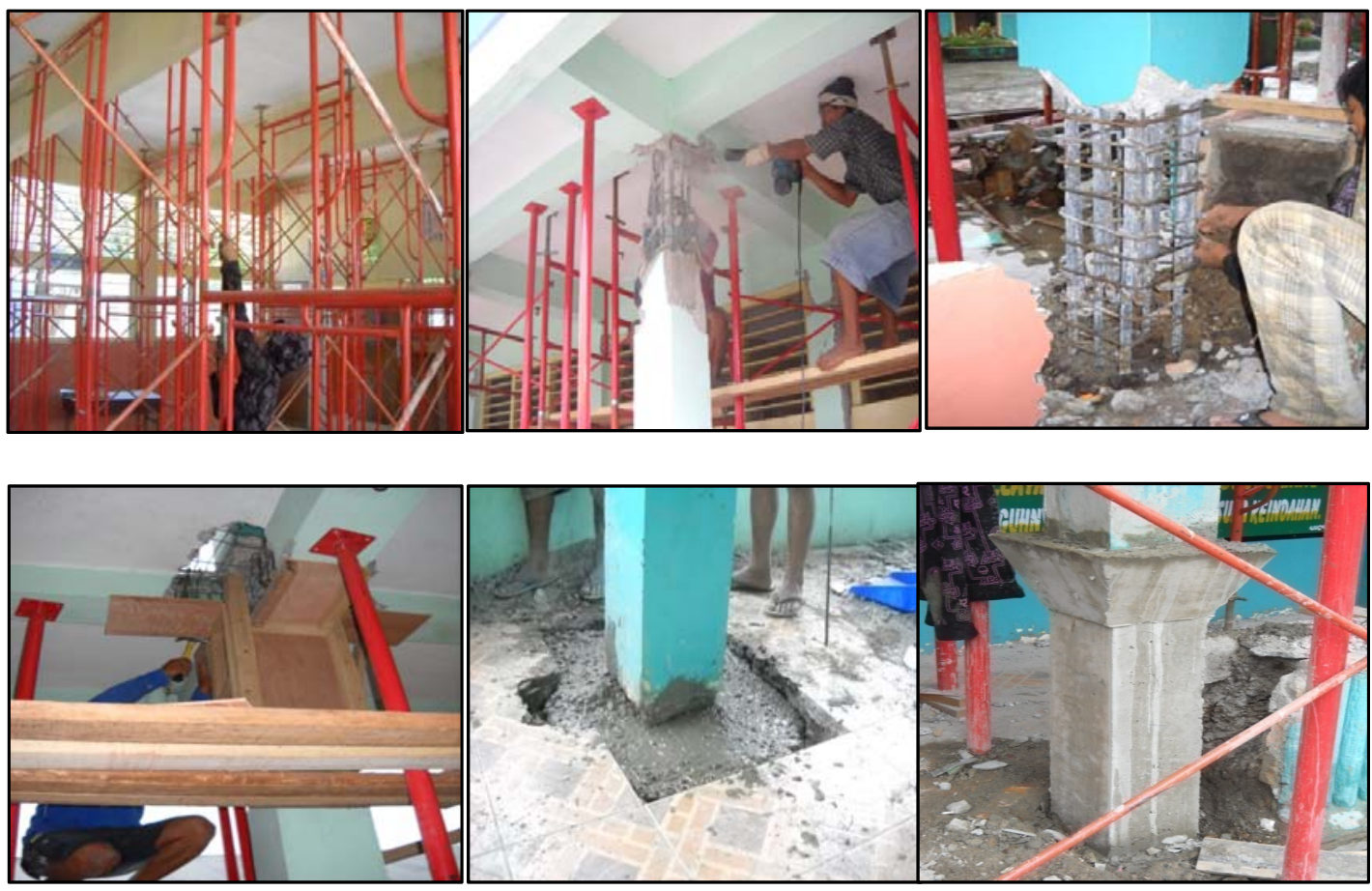

Gambar 7. Langkah-Langkah Retrofit Kolom dan Balok

\section{ANALISIS BIAYA DAN WAKTU}

Dari perhitungan rencana anggaran biaya dan durasi, diperoleh besarnya biaya yang dibutuhkan untuk membangun gedung SD Negeri 43 Rawang Timur adalah Rp.981.471.550,00. Durasi pekerjaan untuk membangun bangunan baru adalah selama 154 hari. Sedangkan dari perhitungan anggaran biaya pekerjaan retrofit, didapatkan biaya Rp.218.1988.300,00, durasi pekerjaan selama 83 hari.

Dari hasil perhitungan tersebut dapat diketahu efisiensipengerjaan retrofit adalah sebesar $22.23 \%$ dari biaya membangun gedung baru. Untuk durasi pekerjaan, didapatkan nilaiefisiensi sebesar $54.00 \%$.

Besarnya efisiensi biaya dan waktu dapat dilihat pada Tabel1. 
Tabel 1. Efisiensi Biaya dan Waktu

\begin{tabular}{|c|c|c|c|c|c|}
\hline No & LuasBangunan & $\begin{array}{c}\text { RAB } \\
\text { BangunanBaru }\end{array}$ & RAB Bangunan Retrofit & $\begin{array}{c}\text { RAB Bangunan Retrofit/RAB } \\
\text { BangunanBaru }\end{array}$ & Efisiensi \\
\hline 1 & $408 \mathrm{~m} 2$ & Rp.981.471.550,00 & Rp.218.918.300,00 & 0.222 & $22.23 \%$ \\
\hline No & LuasBangunan & $\begin{array}{l}\text { DurasiBangunanB } \\
\text { aru (hari) }\end{array}$ & $\begin{array}{c}\text { DurasiBangunan Retrofit } \\
\text { (hari) }\end{array}$ & $\begin{array}{c}\text { DurasiBangunan } \\
\text { Retrofit/DurasiBangunanBaru }\end{array}$ & Efisiensi \\
\hline 2 & $408 \mathrm{~m} 2$ & 154 & 83 & 0.540040478 & $54.00 \%$ \\
\hline
\end{tabular}

\section{KESIMPULAN}

Berdasarkan uraian mengenai kerusakan-kerusakan yang terdapat pada bangunan studi kasus serta pelaksanaan perbaikan dan perkuatan yang telah dilakukan, dapat diambil beberapa kesimpulan:

1. Metode pelaksanaan retrofitting yang efektif dan efisien pada komponen struktur yaitu perbaikan dan perkuatan kolom serta balok gedung SD Negeri 43 Rawang Timur dengan melakukan penjangkaran kolom-balok dan merapatkan sengkang kolom dan balok.

2. Metode pelaksanaan retrofitting yang efektif dan efisien pada komponen non-struktur adalah perbaikan dinding dengan mengisi retak halus dengan air semen, kemudian diplester kembali.

3. Efisiensi biaya pekerjaan retrofit pada gedung SD Negeri 43 Rawang Timur adalah sebesar $22.23 \%$ dari biaya rekonstruksi (biaya membangun baru).

4. Efisiensi durasi pekerjaan retrofit pada gedung SD Negeri 43 Rawang Timur adalah sebesar 54,00\% dari durasi pekerjaan rekonstruksi (biaya membangun baru).

\section{DAFTAR KEPUSTAKAAN}

Badan Meteorologi Klimatologi dan Geofisika (BMKG), (2009).

Boen, T., (2009), ”Cara Memperbaiki Bangunan Sederhana yang Rusak Akibat Gempa Bumi“, Jakarta. 
Analisis Metode PelaksanaanRetrofitting Pada Bangunan Sederhana

\section{0 | J URNAL REKAYASA SIPIL}

